\title{
Socio-Cultural Factors Influencing Entrepreneurial Activities: A Study on Bangladesh
}

\author{
Rahma Akhter ${ }^{1^{*}}$, Farhana Rahman Sumi ${ }^{2^{*}}$ \\ ${ }^{1,2}$ University of Information Technology and Sciences, Bangladesh
}

\begin{abstract}
Development of new business through entrepreneurship directly impact on societies and economies grow and prosper. Although there has been considerable research based on psychological and economic approaches to entrepreneurship, the influence of socio-cultural factors, 1. Religion 2. Ethnicity 3. Family 4. Physical attributes 5. Economic Status 6. Education, make an impact on entrepreneurial development process in developing country. Therefore, the aim of this paper is to put together all factors from a theoretical perspective, the socio-cultural factors and entrepreneurial activity. In this sense, the article points an appropriate framework to develop future research analyzing the socio-cultural factors that influence the decisions to create new businesses.
\end{abstract}

Keywords: Entrepreneurial activity, Entrepreneurship, Entrepreneurial emergence, Socio-cultural environment, Cultural factors

\section{Introduction}

An entrepreneur is a person who always looking for change, responds to change, and exploits it as an opportunity. With adequate requirement of capital, education facility and own creativity, intelligence, energetic youth can be turned into a decent business people. These variables are backed by socio cultural and economic factors of a country.

In Bangladesh, the private sector has a vital role to play in raising the economy and creating employment opportunities. The private sector is the driving gear of innovation in all sectors of the economy. Entrepreneurship in Bangladesh currently thrives in two sectors of the economy -- among the poorest of the poor (14 million households) and among the well-off (about 2.5 million households).

The reason for this is that both of these sectors have access to institutional financing (Syed Mohammod Mostofa Shams-2007). "Entrepreneurship" has a key role to play in developing economies. For a Least Developed Country like Bangladesh, effective entrepreneurial efforts and initiatives can play an vast, noteworthy role in influencing social and economic policy transformation and development outcomes. It has the power to escalation and generates rapid and permanent reductions in poverty. Bangladesh, with its high population density and widespread poverty, is a challenging environment for development initiatives. Huge human resource of the country can be turned to petrol of nation for effective economic growth through exploring entrepreneurial opportunities.

In the past, entrepreneurships have traditionally understood and discussed has been restricted to profitdriven ventures aimed at maximum of return for the entrepreneurs (Campbell, 1992; Caisson,2003). In the modern era, an entrepreneurship is really facing a challenging task because of identifying the business opportunities in anticipating a value addition to the clientele end and yielding profits considering certain social and environmental issue. To run development businesses requires professional skills such marketing, sales and product development. Education is one of the most vital points which make entrepreneur sincere about their economical freedom, their stability and their importance at society. The intention of the paper is to review the issues, initiatives and experiences from social science perspective to develop entrepreneurs in Bangladesh.

\subsection{Objectives of the Study}

The study has been conducted to discover the factors which create barriers, influence or inspire in becoming entrepreneurs. The study has been conducted on the Bangladeshi entrepreneurs and businessperson based on various intangible as well as tangible factors.

The overall objective of this project:

1. Identification and analysis of economic, social and cultural factors which impede the development of entrepreneurial skills development in Bangladesh

2. Explanation of strategies and tools to improve these factors

These objectives are followed on two levels:

1. On the level of the political, social, economic and cultural framework-1. Religion 2. Family 3. Physical attributes 4. Economic Status 5. Education 6. Locality ( Location) 
2. On the level of personal skills of successful entrepreneur.

To reach these overall objectives, the following aims have to be fulfilled:

1. Definition and relevance of the concept of Entrepreneurship and entrepreneurial skills

2. Specification of entrepreneurial skills of entrepreneurs with their social, economic, political and cultural background.

3. Identification and analysis of above factors hindering development of entrepreneurial skills.

\subsection{Concept of Socio-Cultural Environment}

\section{Literature Review}

Socio-cultural environment in broad terms consists of both the social system and the culture of a people. It refers primarily to man created intangible elements which affect people's behaviour, relationship, perception and way of life, and their survival and existence. In other words, the social-cultural environment consists all elements, conditions and influences which shape the personality of an individual and potentially affect his attitude, disposition, behaviour, decisions and activities. Such elements include beliefs, values, attitudes, habits, forms of behaviour and life styles of persons as developed from cultural, religious, educational and social conditioning, ( Bennett and Kassarjian, 1972; Adeleke et.al, 2003 ). These elements are learned and are shared by a society and transmitted from generation to generation within that society.

Thus, social-cultural environment, in relation to entrepreneurship, can be defined as consisting of all the elements of the social system and culture of a people which positively or negatively affect and influence entrepreneurial emergence, behaviour and performance, and entrepreneurship development in general. All such elements which condition the values, thinking and action of an individual with respect to entrepreneurship comprise the social-cultural environment of entrepreneurship.

\subsection{Social factors and entrepreneurial activity:}

Embedded ness and relational networks Understanding entrepreneurship as a social phenomenon allows us to draw on the well-developed more general literatures on social capital and social networks. The concept of social capital is arguably one of the most successful 'exports' from sociology to the other social sciences (Portes, 2000). The origin of the term 'social capital' is credited to Jacobs (1962) and Loury (1977) developed the individualistic and economic conception (Anderson and Jack, 2002; Anderson et al., 2007). Social capital is defined as the tangible and virtual resources that facilitate actors' attainment of goals and that accrue to actors through social structure (Portes, 1999). Given the central proposition that networks of relationships constitute a valuable resource (Nahapiet and Ghoshal, 1998), many of the insights of social capital theory relative to entrepreneurial activity can be found in the social network literature (Casson and Della Giusta, 2007).

In general terms, social networks are defined by a set of actors (individuals and organizations) and a set of linkages between those actors (Brass, 1992). Social networks are the relationships through which one receives opportunities to use financial and human capital - relationships in which ownership is not solely the property of an individual, but is jointly held among the members of a network (Burt, 1992). Social networks are also a set of relationships that can define the perception of a community, whether a business community or a more general notion of community in society (Anderson and Jack, 2002). Thus, society, in the abstract sense, is a series of connected or 'tied' nodes (Narayan and Pritchett, 1999).

This broad conception of social networks and social capital implies that the dynamics of economic exchange are socially embedded (Granovetter, 1985; Portes and Sensenbrenner, 1993). As distinct from rational choice perspectives, the social embedded ness perspective emphasizes that, in embedded contexts, entrepreneurial agency, that is the ability to garner entrepreneurial ideas and the resources to develop them, is shaped by implicit norms and social mores. Thus, social capital is conceptualized as a set of resources embedded in relationships (Burt, 1992). This idea raises interesting questions revolving around the entrepreneurial applications of social capital, in particular, in relation to some less desirable consequences. For instance, the exploitation of social capital by any one person or entrepreneur, even within contextual rules, if any, implies both winners and losers (Anderson and Jack, 2002). Related to this idea, Portes and Landolt (2000) identified four negative consequences of social capital: exclusion of outsiders, excess claims on group members, restriction on individual freedoms and downward levelling of norms. As an example, these authors point out that the same strong ties that enable group members to obtain privileged access to resources bar others from securing the same assets. In a similar vein, the particularistic preferences granted to members of a clan or circle of friends are commonly at the expense of the universalistic rights of others. This phenomenon of unequal rights to entrepreneurial resources often frames the differences among ethnic entrepreneurial groups, or among entrepreneurs in different regions or countries (e.g. developing countries). This view of social capital is closely associated with the emphasis placed by Coleman 
(1993) on community structures as a mechanism of social control, which, in turn, is also linked with the predominant culture in a specific society.

Within the field of entrepreneurship many studies have drawn on social network analysis to illustrate entrepreneurs' access to resources that are not possessed internally (Bowey and Easton, 2007; Casson and Della Giusta, 2007; Ostgaard and Birley, 1994). The underlying idea is that, although entrepreneurs usually hold some of the resources necessary to create a business (e.g. ideas, knowledge and competence to run the business), generally they also need complementary resources which they obtain through their contacts (e.g. information, financial capital, labour) to produce and deliver their goods or services (Aldrich and Zimmer, 1986; Cooper et al., 1995; Greve and Salaff, 2003; Hansen, 1995; Ribeiro-Soriano and Urbano, 2009; Teece, 1987).

In the entrepreneurship network literature, three elements of network relations stand out as critical to theoretical and empirical research on the entrepreneurial process (Hoang and Antoncic, 2003; Johannisson, 1988, 1998): the nature of the content that is exchanged between actors (e.g. social capital and intangible resources, such as emotional support) (Bates, 1997; Light, 1984; Zimmer and Aldrich, 1987), the governance mechanisms in network relationships (e.g. trust between entrepreneurs and venturing partners) (Larson, 1992; Lorenzoni and Lipparini, 1999), and the network structure created by the crosscutting relationships between actors (e.g. the ability to use cohesion and structural holes to $\begin{array}{lllll}\text { discover and develop entrepreneurial returns) } & \text { (Burt, }\end{array}$ Hansen, 1995).

\subsection{Cultural factors and entrepreneurial activity}

Because societies are endowed by nature with different physical environments, members of society must adopt environmentally relevant patterns of behavior to achieve success. These environmentally relevant patterns of behavior lead to the formation of different cultural values in different societies, some of which influence the decision to create new businesses. Thus, culture, as distinct from political, social, technological or economic contexts, has relevance for economic behavior and entrepreneurship (Shane, 1993; Shapero and Sokol, 1982).

One of the difficulties in examining the cultural affects and effects in relation to entrepreneurial activity is the lack of a precise and commonly understood definition of culture (McGrath et al,1992). Anthropologists suggest that culture is related to the ways in which societies' organize social behaviour and knowledge (Hall, 1973; Kroeber and Parsons, 1958). Cultural values are defined as the collective programming of the mind which distinguishes the members of one human group from another and their respective responses to their environments (Hofstede, 1980).

Several studies have stressed the influence of cultural factors on entrepreneurship from different perspectives. Hayton et al. (2002), in their literature review, link culture and entrepreneurship to three broad streams of research. The first focuses on the impact of national culture on aggregate measures of entrepreneurship such as national innovative output or new businesses created. The second stream addresses the association between national culture and the characteristics of individual entrepreneurs. The third explores the impact of national culture on corporate entrepreneurship.

Accordingly, when an individual creates a business in a specific cultural environment, this business reflects that cultural environment, for example characteristics such as strategic orientation and growth expectations for the business.

Much of the research in entrepreneurship that considers cultural variables has followed Hofstede's $(1980,2001)$ seminal work showing how culture is manifested in various forms, and how cultural values at individual or societal levels are influenced by national culture. According to this view, cultural differences across societies can be reduced to four quantifiable dimensions:uncertainty avoidance, individualism, masculinity and power distance. The dimension of uncertainty avoidance represents preference for certainty and discomfort with unstructured or ambiguous situations. Individualism stands for a preference for acting in the interest of one's self and immediate family, as distinct from the dimension of collectivism, which stands for acting in the interest of a larger group in exchange for their loyalty and support. Power distance represents the acceptance of inequality in position and authority between people. Masculinity stands for a belief in materialism and decisiveness rather than service and intuition. Using Hofstede's (1980) concept of culture, researchers have in general hypothesized that entrepreneurship is facilitated by cultures that are high in individualism, low in uncertainty avoidance, low in power-distance and high in masculinity (Hayton et al., 2002).

Anthropologists view entrepreneurship as well as other social processes as cultural processes (e.g. Greenfield and Strickon, 1986; Stewart, 1991). In particular, the important role of norms and traditions has been demonstrated, which, although they generally do not inhibit entrepreneurship, can do so. From an anthropology 
perspective, attention to social and cultural factors related to the creation of a new business has provided interesting contributions to the understanding of entrepreneurship, especially through the study of social constraints (Garlick, 1971; Kennedy, 1988; Wiewel and Hunter, 1985) and collective approaches (e.g. family business, community-centred business, ethnic or organizational entrepreneurship) to business formation and growth (Benedict, 1968; Davis and Ward, 1990; Kleinberg, 1983; Parker, 1988, among others).

In sum, central approaches to understanding the role of social and cultural factors revolve around the concepts of 'networks' and 'embeddedness' (Granovetter, 1985, 1992), and the research stream based on Hofstede's $(1980,2001)$ dimensional cultural framework.

Although, in general the research has shown cultural variables to have an influence on entrepreneurship, cultural variables in many cases have been theorized and modeled as moderating of entrepreneurial outcomes (Hayton et al., 2002). This suggests that greater attention should be given to the interactions among cultural dimensions and the conception of culture that allows for greater complexity in relation to other characteristics of the environment.

The effects of such cultural complexity are being explored by an eclectic group of economists and sociologists around the idea of how culture provides justifications for individuals' actions and results in economies of worth to us all collectively (Berger, 1991; Carsrud and Johnson, 1989). In contrast to the Parsonian conception of culture as a relatively monolithic force within a nation and Hofstadter's dimensions developed from data in the corporate setting, these scholars view culture as fragmented by institutional orders which may or may not align with national culture (Busenitz et al., 2000; DiMaggio, 1997).

According to this view, the major domains of life and how they affect entrepreneurial behavior are conceptualized and measured within the context of distinct institutional orders - for example the family, the religions, the market, the professions, the state and the corporation (Thornton, 2004; Thornton and Ocasio, 2008). These institutional orders embody competing and conflicting sources of norms, values, legitimacy and justifications of worth that have consequences for supporting or discouraging entrepreneurial behavior.

Elements of these institutional orders are potentially decomposable and transposable into new contexts. This modularity implies that culture, rather than being consistent in values, can be quite inconsistent, if not awkward in manifesting value clashes and role ambiguities that become particularly visible when elements are transposed from one institutional order to another. For example, the family and the market as institutional orders embody values that organize behavior and knowledge in quite different ways. Fried land and Alford (1991: 248) exemplify this argument with the simile that, 'acting like one was selling a used car at the family dinner table would draw

scorn

while treating a used car salesman like a family member would lead to exploitation'. This simile illustrates that individuals and organizations have the capacity to loosely couple and manipulate elements of culture - using them strategically as if they were a 'tool kit' (Boltanski and Thevenot, 1991; DiMaggio, 1997; Swidler, 1986; Thornton, 2004). Scholars are beginning to use variants of this line of cultural theory in quantitative research that explains the intention to start a business in different cultures (Klyver and Thornton, 2010).

\subsection{Socio-Cultural Theories of Entrepreneurial Emergence}

Over the years, a number of theories have been used to explain the impact of socio-cultural environment on entrepreneurial emergence. The theories tried to explain the social and cultural characteristics which cause people to be or not to be entrepreneurs. The earliest theory on the influence of socio-cultural environment on entrepreneurship was that of Max Weber, a German sociologist. In his theory, Weber explained that society plays a big role in developing entrepreneurs. This is because the individual draws his values from the social values, mores and institutional framework within which he lives (Van de Ven, 1993). He argues that culture has great impact on the attitude and behaviour of individuals and their disposition to life. And indeed, whether or not an individual would develop and become entrepreneur would depend on his disposition and value orientation. He cited religion as an element of culture which directly influence the behaviour of individuals towards being entrepreneurs. Such religious characteristics as hard work, thrift and an ascetic life of self denial are all prescription for entrepreneurship.

Essentially, the point of Weber's theory is that the socio-cultural systems in which individuals live provide a set of values from which personal values and thinking pattern of people are based, and these in turn influence the decision by individuals positively or negatively towards entrepreneurship, i.e. whether or not to be entrepreneurs. Fundamentally, social systems and culture affect the development of entrepreneurial spirit and motivation by exhibiting values that either enhance or inhibit entrepreneurship behaviour and drive amongst people.

Since the theory of Max Weber, the analysis of entrepreneurial emergence has attracted a great deal of theorizing among scholars trying to identify and explain the foundation on which entrepreneurs emerge. The general opinion is that emergence of entrepreneurs is a function of a number of motivational factors or 
conditions. However, there is a divided thought among scholars regarding these factors. Before now, the literature was dominated by the view that individuals who emerge as entrepreneurs are frequently individuals of a poor background, mostly with low level of education, but with a 'burning' desire for upward social mobility and recognition. Although this view seems outdated and incorrect but it makes a lot of meaning with regards to influence of social conditions in the making of an entrepreneur.

\subsection{Family orientation theory}

The theory posits that factors such as family background and orientation are sources for entrepreneurial characteristics and the emergence of entrepreneurs. The theory emphasized the role of the family in developing the entrepreneurial character. It is believed that the home atmosphere and values of an entrepreneurial family can provide a great deal of nurturing and support for development of entrepreneurial personality or character (Kuratko 1989). This is so because the family background of an individual is a strong influence on his values and character and therefore serves as a strong source of influence whether he would be an entrepreneur or not. "This reasoning promotes the belief that certain traits established and supported early in life will lead eventually to entrepreneurial emergence and success (Kuratko and Hodgetts, 1998).

\subsection{Educational incubation theory}

The educational incubation theory posits that educational development aids entrepreneurial emergence through creation of awareness and new orientation and knowledge. It is contended that societies with high level of education tend to produce more entrepreneurs than societies with less educated people. The advanced countries are cited examples of such societies.And it is for this reason that educational development has attracted increase emphasis in many societies (Kuratko and Lafollette, 1986), (Kuratko, 1989) and (Block and Stumpf, 1992).

\subsection{Integrating social and cultural factors and entrepreneurial activity: An institutional perspective}

This literature review reinforces the view that the problem of integrating analyses of the social and cultural factors that affect entrepreneurship is challenging. A growing number of scholars are developing institutional approaches to explain various topics of entrepreneurship and SMEs (Aidis, 2005; Anderson, 2000; Busenitz et al., 2000; Djankov et al., 2002; Hardy and McGuire, 2008; Kalantaridis, 2007; Lerner and Haber, 2001; North et al., 2001; Pugh and Dehesh, 2001; Stephen et al., 2009; Urbano, 2006; Wai-Chung, 2002; Welter, 2005). Because institutions are constituted by culture and social relations, and because human, social and cultural capital are often antecedents to acquiring financial capital and other resources needed to start a business, an institutional approach with its broad metatheory holds out the promise of developing future entrepreneurship research.

Various theories and methods of institutional analysis are used in the different branches of the social sciences for example, in sociology, political science and economics (Scott, 2008). There is considerable variance in the definition of an institution, and in the analytical methods used by scholars to study institutions and their effects. At the baseline, we define institutions as establishing a stable structure for human interaction. Scott (2008: 33) suggests that institutions consist of cognitive, normative and regulative structures and activities that provide stability and meaning in social behavior. Institutions are the rules of the game in a society that function as constraints and opportunities shaping human interaction (North, 1990: 3). Applied to the field of entrepreneurship, institutions represent the set of rules that articulate and organize the economic, social and political interactions between individuals and social groups, with consequences for business activity and economic development (Díaz et al., 2005; Veciana and Urbano, 2008). According to North (1990), institutions can be formal, such as political and economic rules and contracts, or informal, such as codes of conduct, conventions, attitudes, values and norms of behaviour. Formal institutions are subordinate to informal institutions in the sense that they are the deliberate means used to structure the interactions of a society in line with the norms and values that make up its informal institutions. North's definition implies that policy-making which attempts to change the formal institutions of society without measures to adjust the informal institutions in compatible ways will have marginal success. For example, difficulties arise when a governing body can influence the evolution of society's formal institutions in a direct way, yet the less tangible informal institutions remain unaltered outside the direct influence of public policy. While informal institutions can be shaped, they are likely to resist change and take time to evolve towards new social norms. For example, 'radically different' performance of economies can exist over long periods of time as a result of the embedded character of informal institutions (North, 1990, 2005)

Sociologists (DiMaggio, 1988; Scott, 2008; Thornton, 1999) extend this economic view of the distinction between formal and informal institutions arguing that the gap or lag between formal and informal institutions, potentially generated by corporate and public policy-makers, can give rise to 
an unintended consequence. In the sociologist's parlance (Thornton, 1999), this is a 'loose coupling' effect caused when individuals and organizations decouple elements of culture or layers of organizational structure to avoid the conflict that such an incompatibility may present. Such decoupling, for the 'institutional entrepreneur', can be the genesis for new combinations of institutional and organizational parts from the entrepreneurial landscape (DiMaggio, 1988; Meyer and Rowan, 1977). Hence, both formal and informal institutions can legitimize and delegitimize business activity as a socially valued or attractive activity - and promote and constrain the entrepreneurial spirit (Aidis et al., 2008; Veciana and Urbano, 2008; Welter, 2005). In summary, the different varieties of institutional approaches provide an overall meta-theoretical framework for integrating an under-standing of the contributions of the socio-cultural factors in entrepreneurship research, as well as suggesting avenues for future research.

\subsection{Research Design}

\section{Methodology}

This paper is based on secondary data, primarily through literature review and targeted interviews with the key informants from cross-section of people and experts. Focus Group Discussion (FGD) method has been applied to collect information on different entrepreneur's situation. In addition, case study method is used to collect in-depth information on this issue. The data are fairly consistent and reliable, although there are some discrepancies between government and non-government sources. The emphasis has been given on qualitative analysis but some quantitative data has been used to supplement the qualitative analysis.

Overall this exploratory research tries to explore the existing condition of the variables and relationship among them in a real world application of Bangladesh. Both qualitative and quantitative research approaches and procedures have been applied to explore pertinent information for this study.

\subsection{Religion \& Entrepreneurship}

\section{Analysis and discussion}

Internationally it has been observed that two religions, Buddhism and Judaïsm, have positive direct and indirect institutional effects as well as busienss network effects. That Buddhism is so positively and constantly correlated with international trade would not surprise Lal (1998), who argues that the examples of Japan after World War II, and China, India, and many other Asian economies. More recently it proves that rapid economic growth can be achieved in non-Western societies. The result that the Hindu culture does not generate any noticeable network effect is surprising, given the Hindu Diaspora throughout Asia, Africa and the Caribbean. Perhaps the mixed results are driven by the remnants of the Hindu culture's divisive catse system, or, aus Uppal (1986) and Eisenstadt (1968) note, the culture's lack of a single unifying written doctrine.

Bangladesh is a secular republic and a melting pot of different faiths. There is good integration of religions in the society, which is demonstrated by people's sharing in the festivities of all religions. History of Bangladesh has a major role to play in this. Muslims, Hindus, Christians and Buddhists have all lived in Bengal for long periods of time.The area that is now Bangladesh has been civilized for the last 4500 years. The Aryan tribes lived here around $2500 \mathrm{BC}$. Then the Buddhists came and stayed permanently all over Bengal. The Hindus then built their empires here. And then the Arabs and the Turks came and introduced Islam to Bengal. By the 16th century, the Mughal Empire, originally from the far north, made Bengal their home and further influenced the religious beliefs of the people. Islam is the presently the official religion in Bangladesh and is practiced by some $88 \%$ of the country's inhabitants. The majority of the populations pursue the Sunni branch of the Islam.

Religion can impact on entrepreneurship business in several ways. First, religion is a cultural institution that drives human behavior. In Islamic religious culture encourages hard work and commercial activities. However Islamic religion is discourage interest on loan. For a entrepreneur, Bank support and skill knowledge both are core components for business development. In this connection, Islamic banking may have a solution but psychological negative impact remains in entrepreneur's mind regarding interest on finance. in Bangladesh. Muslim and Hindu cultures are dominant in the country. Sometimes religious cultures are creating obstacles in practicing business. For example. fishing, saloon and leather business are not yet developed due to this problem. Some drugs are also prohibited by the religions. Tourism had a strong effect on alcohol consumption and electronic gambling machine when availability, income were controlled. Again alcohol consumption is positively correlated with both the duration of play and probability of participation for gambling.( Markham, F, Young, M \& Doran, B 2012, 'The relationship between alcohol consumption, gambling behaviour and problem gambling during a single visit to a gambling venue', Drug and Alcohol Review, vol. 31, no. 6, pp. 770-777.) Alchohol beverage and gambling both are strictly prohibit in Islam. It is one of the main reason to under develop tourism sector in Bangladesh which results entrepreneurs are losing opportunities from tourism industry. 


\subsection{Socio-Cultural features \& Entrepreneurship}

In Bangladesh socio-cultural environment it reveals that the society culture is characterized by number of features which have influenced entrepreneurial emergence either positively or negatively. The socio-cultural features of Bangladesh are presented and discussed under the various levels as follows:

\subsubsection{Bangladeshi Conventional Culture and Social Features}

Traditional beliefs and value system, fatalistic attitude, religiosity are include in this category. Social problems such as literacy level and poverty resulting from high unemployment or joblessness among people observe in the society. It is also observed that these value elements make a significant impact on level of entrepreneurial emergence in Bangladesh as indicated by the economic growth and development in contrast with western nation.

\subsubsection{Education level}

Literacy has often been defined as those aged 15 and older who can read and write. The overall literacy rate for Bangladesh is 56.5\% (Wikipedia 2011). This is a significant rise from 29.2\% in 1981 (Bangladesh Literacy Rate, 2011). A 2008 UNICEF estimate of gender disparity indicates that the literacy rate for men is $62 \%$ and $51 \%$ for women (Wikipedia, 2011). The Bangladesh Government and various NGOs have invested significantly to uphold the standard of education level and literacy rate. There is a contrast between the situation in the past and the present. In the past the demand for education was low because of the low value attached to education by families in rural area as an immediate means of wealth creation. Another reason was involvement of financial cost. Major population therefore took, mainly to trading, craft, farming and vocations as profession. The situation facilitated the emergence of entrepreneurs of that time. After independence of 1971, the size of educated population was small and was able to secure employment in the available industries and the public sector (civil service) of first three decades. Unemployment didn't exist at high level. Educated persons didn't see it meaningful to create businesses for themselves and be self employed.

Now there value for education is growing, therefore, the desire for education by Bangladeshi people, have risen. The society's demand for education increases and people get more educated than earlier time. It is observed that the business volume and ownership relation to the total population are reducing. This feature implies that higher education is affecting negatively entrepreneurial emergence in Bangladesh. People with high education are more eager in search of job placement in existing industries than creating new businesses of their own. Political unstable situation, corruption, ample requirement of capital to establish business may major factors effect the emergence of entrepreneurship. Self employment considering the challenges of business Bangladesh environment, success is not confirm and may be at slow rate. To do job in a big company ensures the certainty of income and faster in placing in respective position in the society. Hence there are lots of people in Bangladesh having no or less education but owning businesses than people with high level of education. Meritorious graduates are hardly in business of their own. The task of entrepreneurship requires both education and courage as essential ingredients. A literate society does not robotically convert to an entrepreneurial society. Specialized entrepreneurship education with emphasis on vocational/ technical training supported with the provision of available infrastructures.

\subsubsection{Poverty}

Poverty has had both constructive and unconstructive influence on entrepreneurial coming out in Bangladesh. The general level of poverty in Bangladeshi society impedes a large proportion of the poor population into entrepreneurship. The number of people may have been inhibited entrepreneurship by their lack of fund. The numbers of people have been pushed into entrepreneurship to survive and get out of poverty. Thus in reality the general state of poverty in the society has more unconstructive than constructive effect on emergence of entrepreneurs. A major cause of poverty in Bangladesh is the high unemployment level in the society. In the past, the educated people had no need for self employment since they could get well paid job at ease. But at present situation experience of unemployment has pushed people to think establishment of new business and the formation of own business. As a result of the socio-economic sufferings and embarrassment of unemployment, many people have changed their orientation in favour of entrepreneurship particularly since the 1990s. The emergence of garments sector in Bangladesh was mainly developed at that time. Since the early 1990 s, the knit section of the industry has started to expand. Shirts, T-shirts, trousers, sweaters and jackets are the main products manufactured and exported. Entrepreneurs export its RMG products mainly to the United States of America and the European Union. Now these sector accounts for more than a $80 \%$ share of the country's total earnings from garment exports. It is observed that since 1990's there has been an increase in entrepreneurship business in general and within the educated class in particular, especially small and medium size businesses. There are more youths who now than ever before have possession of businesses in all aspects of industry. The growth in the service, fashion and hospitality/entertainment industries as well as commerce, is a 
evidence to this. Impliedly, the current social problem of unemployment has influenced positively the emergence of entrepreneurs particularly among the educated people of Bangladesh.

\subsubsection{Gender Role Values}

Socio-cultural influence on entrepreneurship is also noticeable from the point of view of entrepreneurship among women in Bangladesh. Generally, the function of men and women in various environment of business varies widely. Certainly, in many societies women do not enjoy equivalence with men as participants in the economy especially in rural area. The extent to which women are allowed to participate in business activities affects their drive to become entrepreneurs. Also, values about family role for men and women affect entrepreneurial emergence between men and women. It determines how families divide responsibilities for $\mathrm{t}$ well being of the family unit. This varies among cultures to culture, society to society. While in some societies and cultures the men are given the total role of economic related business and the women restricted to administering work in the family, in other societies earning responsibility for the family is borne by both the man and the woman, thus allowing the woman a space to engage in entrepreneurial activities. In Bangladesh, the traditional beliefs about the role of women do not allow to engage in serious economic activities. In rural area of Bangladesh, It is believed that the woman's role is in the home and engaging in activities outside the home is going against norms and values of the religion and culture. This point of view has accounted for the low level of entrepreneurship among Bangladeshi women particularly in rural area. In other words, the society should be allowed women own and run businesses and they should communicate with the public. Exception of this cultural belief has negative influence on entrepreneurial drive among women in the rural and urban area of Bangladesh. The low level of entrepreneurship among women in Bangladesh attributed to the general belief among their men that business women are laying face down to sexual abuse by men. This makes them to discourage women from business activities to avoid them being in contact with men. As a result, the emergence of women entrepreneurship slows down in the society.

\subsubsection{Peer Group Influence to be an Entrepreneur}

Workplace peers are one important influence to become entrepreneur. Those who work with former entrepreneurs are more likely to start their own businesses with similar industry. In Bangladesh, there is evidence of many business personnel in garments industry who worked previously as an employee in the same industry. Sometimes it takes to become motivated to be an entrepreneur.

To get success of entrepreneurs need resources. People whose co-workers have worked in a variety of places as an successful entrepreneur are also more likely to become entrepreneurs. Colleagues, even through informal conversations, can help peer group to coming out as an entrepreneur to launch a new venture. Peer influences were most pronounced for entrepreneurs who did not have entrepreneurial parents. Entrepreneurs with family business have already owned their businesses and it's become easy for them to expose the idea of entrepreneur's as a viable career option. Entrepreneurial activity is related to the prior career experiences of an individual's peer members. Individuals can perceive entrepreneurial opportunities as well as increase their motivational level to pursue those opportunities. Individual is more likely to become an entrepreneur if his or her peer member have been entrepreneurs before. Family influences appear to be substitutes for other sources of entrepreneurial influence: Peer influences are strongest for those who have less exposure to entrepreneurship in other aspects of their lives.

\subsubsection{Political Instability}

Social and political instability are and were almost all the countries of the contemporary world. Political instability must be kept under control for entrepreneurial development of the country. There is already continuing crisis in the Bangladesh economy in the form of continuing gas-electricity crisis, high interest rate, scarcity of land for industrialization, labor unrest, corruptions etcetera and ongoing serious political instability to accelerate the deterioration of business development farther. Political crisis is so intense influence in business that the country's economy is about to crack down. The people are naturally very much concerned and alarmed at the increasing incidents of sabotage, loss of life and property for political instability. Mills-factories and the overall production process become stagnant due to instability. Entrepreneurs are generally getting back to establish new project or extent their new venture. Shops and businesses have become sterile. Bangladesh will have to solve the problem in its own way. Economic crisis is all around there in Bangladesh these days. Especially the banking and financial institutions are under threat due to stagnant situation in business. Financial institutions are authorized body to solve equity problem of entrepreneurs whereas these institutions are under in threat due to political instability. Political crisis is so intense in business nature that the country's economy is about to crack down. If there are healthy political culture and congenial law and order situations in the country, the economy will be healthy and the common people will be in frame of mind for investment of new venture. So the politicians will have to be responsible, cautious and mindful to create an friendly business environment so 
that more entrepreneurs are come out to establish a new business. Supply of commodities must be uninterrupted, export commodities can reach the ports, the business community can function properly. The government is continually raising the prices of fuel oil to make commensurate with international price. This impedes productions. It is necessary that an investment friendly atmosphere is created in the economy. In addition the rate of interest needs also to be sustainable and investment oriented. Political instability that prevails in the country, social restlessness, insufficiency of electricity supply, strikes, besieging, huge loss of public and private properties, communal riots are not at all good messages for entrepreneurship development

\section{Conclusion}

The analyses discovered primarily that socio-cultural factors can influence both positively and negatively entrepreneurial emergence in a society. The references in the analysis confirm opinions in the theories of entrepreneurial emergence which are rooted in the theory of social behavior. It also focuses on values and occurrences that the behavior and the individual decision process is being influenced and motivated by socio cultural aspects. The lifestyles including social and economic conditions are also influenced as indicated in the study. An individual person with his distinct characteristics influences the society as well. The socio cultural environment has all its dynamics to influence the environment as well as individual values which directly influence his decisions and actions in all endeavors.

The study reveals the impact of socio-cultural environment on entrepreneurship poses a challenge about the need for the Bangladeshi society to have new values and orientation favorable to entrepreneurship and emergence of entrepreneurs. Day by day new challenges are emerging and the society is fighting to accept and convert it into a facility. The Bangladeshi socio-cultural system should be reengineering its societal values be undertaken to get people out of the traditional ties, negative attitudes and behavioral pattern, to develop a new set of positive values that attract and facilitate entrepreneurial emergence. It will give the society an option to convert challenges into opportunities.

\section{Bibliography}

[1]. Adeleke, A., Oyenuga, O.O. and Ogundele, OJ.K. (2003). Business Policy and Strategy. Mushin, Lagos:Concept Publications Limited.

[2]. Abdin, MJ 2010, Bangladesh's SMEs facing so many challenges, the independent, http://theindependentbd.com/paperedition/others/ panorama/2385-bangladeshs-smes-facing-so-manychallenges. html, accessed on 16 October, 2011.

[3]. Ahmed, R, \& Chaudhury, H, 1980. Female Status in Bangladesh. Bangladesh Institute of Development Studies: Dhaka, Bangladesh.

[4]. Abdullah, Mohammad (1996). Entrepreneurship Development in Light Engineering Industries in Bangladesh: Problems and Policies. Management Development 25 (3) July-September.

[5]. Beugelsdijk, S. and N.G. Noorderhaven (2005). Personality characteristics f self-employed; An empirical study, Small Business Economics, 24, 59-167.

[6]. BBS, 1996, Labour Force Survey, Bangladesh Bureau of Statistics, Statistical Division, Ministry of planning, Government of the People's Republic of Bangladesh, 1995-1996 pp. 48.

[7]. Block, Z. and Stumpf, S.A. (1992). Entrepreneurship Education Research: Experience and Challenge in The State of the Art of Entrepreneurship, ed. Sexton, D. L and Kasarda, J.D, Boston MA: PWS-Kent.

[8]. Birley S (1985). The role of networks in the entrepreneurial process. Journal of Business Venturing 1(1): $107-117$.

[9]. Bruno, A. V. and T.T. Tyebjee (1982). The Environment to Entrepreneurship. In The Encyclopedia of Entrepreneurship, C.A. Kent et al. eds. New Jersey: Prentice Hall.

[10]. Carter, S, and Rosa, P 1998. The Financing of Male- and Female-owned Businesses, Entrepreneurship \& Regional Development 10(3), pp. 225-241.

[11]. Choudhury, TA, Raihan, A 2000. Structural Adjustment Participatory Review Initiative Bangladesh, Study Theme 2(C): Implications of Financial Sector Reforms, The World Bank, Government of Bangladesh and Civil Society.

[12]. Collins R (1997). An Asian route to capitalism: Religious economy and the origins of self-transforming growth in Japan. American Sociological Review 62: 843-865.

[13]. Gilad, B. and Levine, P. (1986). A Behaviourial Model of Entrepreneurship Supply, Journal of Small Business Management, Vol.24.No.4, pp 45-53.

[14]. Goswami, Arun Kumar 1998. Empowerment of Women in Bangladesh, Empowerment: A Journal of Women for Women, Vol. 5, pp. 45.

[15]. Greenfield SM and Strickon A (1986). Introduction. In: Greenfield SM and Strickon A (eds) Entrepreneurship and Social Change. Lanham, MD: University Press of America, 4-18.

[16]. Heilbrunn, S 2004. Impact of Gender on Difficulties Faced by Entrepreneurs, International Journal of Entrepreneurship \& Innovation 5(3), pp. 159-165.

[17]. Hisrich, R. D. and Peters, M.P. (2002). Entrepreneurship (5th ed.). Irwin, London: McGraw-Hill,

[18]. Hofstede, G. (1984). Culture's Consequences. Beverly Hills: Sage, CA.

[19]. Jesselyn, Mary 2004. The Formal Institutional Framework of Entrepreneurship In The Philippines: Lessons for Developing Countries, The Journal of Entrepreneurship, Vol. 13(2), pp. 185-203.

[20]. Katz, JA 1991. Endowed Positions: Entrepreneurship and Related Fields, Entrepreneurship Theory and Practice, Vol. 15(3), Spring, 53067.

[21]. Kearney, P, 1996. The Relationship Between Developing of the Key Competencies in Students and Developing of the Enterprising Student, Paper commissioned by Department of Employment, Education, Training and Youth Affairs, Canberra, Australia.

[22]. Kuratko, D.F. and Hodgetts, R.N. (1998). Entrepreneurship: A Contemporary Approach. Orlando, U.S.A.: The Dryden Press, Harcourt Brace College Publisher. 
[23]. McQuiad, RW 2002. Entrepreneurship and ICT Industries: Support from Regional and Local Policies, Regional Studies, Vol. 36(8), pp. 909-919.

[24]. Meredith, G.G., Nelson, R.E. and Neck, P.A. (1991). The Practice of Entrepreneurship. Lagos: University of Lagos Press.

[25]. Khondker, Mubina (1992). Entrepreneurship Development and Economic growth: The Bangladesh Case. Dhaka University Journal of Business Studies, 13 (2): 199-208.

[26]. Niemann, Y, \& Romero, A, 2000. Effects of Cultural Orientation on The Perception Of Conflict Between Relationship And Education Goals For Mexican American College Students, Hispanic Journal of Behavioral Sciences, 22, Pp. 46-53.

[27]. Parker B (1988) Moral economy, political economy, and the culture of entrepreneurship in highland Nepal. Ethnology 27: 181-194.

[28]. Rahman, Habibur A.H.M. (1989), Profile of Bangladeshi Entrepreneurs. Bangladesh Business Research Report, University Grants Commission, Vol. 1: 67-80.

[29]. Rosa, P 1992. Entrepreneurial Training in the UK: Past Confusion and Future Promise. Scottish Enterprise Foundation Conference Paper Series, Nos. 81-92, Sterling University, Scotland.

[30]. Schwartz, S.H. (1994). Beyond Individualism/Collectivism: New cultural dimensions of values, in Kim et.al(eds Shane S (1993) Cultural influences on national rates of innovation. Journal of Business Venturing 8: 59-73.

[31]. Soliaman, Mohammad. and S. R. Hilaly (1997), Problems and Prospects of Entrepreneurship Development of Muslim Ummahs: The Case of Bangladesh. The Cost and Management, November-December),

[32]. Thurik, R. and M. Dejardin (2011), Entrepreneurship and culture, in: E.Masurel and M. van Gelderen, eds, Entrepreneurship in Context, London:

[33]. Routledge, to appear.UNDP 2004, "Human Development Report 2004”, Oxford University Press.

[35]. Van de ven, A.H. (1993). The development of an Infrastructure for Entrepreneurship, Journal of Business Venturing, May. 